Ich füge noch bei, dafs ich hei Gelegenheit dicser Untersuchung das Erythrin auf sein Verhalten zu polarisirtem Licht geprüft habe, jedoch nicht im Stande war, bei einer Lösung der Substunz von $p=2$ in 97 vpC. Alkohol bei $15^{\circ} \mathrm{C}$. eine Ablenkung der Ebene des polarisirten Lichteg zu bemerken. Das Erythrin wird hitrnach für optisch inactiv gelten müssen.

\title{
Ueber Amidomethylenbrenzcatechine;
}

\section{ron Demselben.}

Nitropiperonylsäure wird in wässeriger Lōsung durch Zinnfeile und Salzsäure leicht reducirt. Sobald die anfänglich gelbe Lösung farolos geworden ist, wird das gelöste Zinn durch Schwefelwasserstoff weggenommen und die klar filtrirte Lösung bei gelinder Temperatur abgedampft, worauf bei starker Concentration der Lösung das salzsaure Salz des Monamidomethylenbrenzcatechins auskrystallisirt. Die Reaction erfolgt mithin nach folgender Gleichung :

$$
\mathrm{C}_{8} \mathrm{H}_{8}\left(\mathrm{NO}_{2}\right) \mathrm{O}_{4}+6 \mathrm{H}=\mathrm{C}_{7} \mathrm{H}_{5}\left(\mathrm{NH}_{3}\right) \mathrm{O}_{2}+2 \mathrm{H}_{8} \mathrm{O}+\mathrm{CO}_{2} \text {. }
$$

Das gleiche Product entsteht bei Einwirkung von Zinnfeile und Salzsäure auf Nitromethylenbrenzcatechin.

Das aus wenig heifsem Wasser umkrystallisirte Salz ist wasserfrei. Es gab bei der Analyse von :

$0,2198 \mathrm{Grm}$. Substanz bei $100^{\circ}$ getrocknet $0,391 \mathrm{CO}_{2}$ uod $0,092 \mathrm{H}_{2} \mathrm{O}$. 0,1773 AgCl.

Diese Resultate entsprechen der Formel $\mathrm{C}_{7} \mathrm{H}_{7} \mathrm{NO}_{2}, \mathrm{HCl}$, welche :

\begin{tabular}{|c|c|c|}
\hline \multirow{6}{*}{$\begin{array}{l}\mathbf{C}_{7} \\
\mathbf{H}_{8} \\
\mathbf{N} \\
\mathbf{O}_{8}\end{array}$} & \multicolumn{2}{|c|}{ verlangt } \\
\hline & 84 & 48,41 \\
\hline & 8 & \\
\hline & 14 & \\
\hline & 32 & 18,46 \\
\hline & 35,5 & 20,46 \\
\hline & 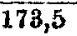 & \\
\hline
\end{tabular}

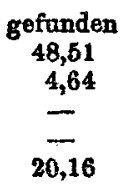


Das salzsaure Monamidomethylenbrenzcatechin krystallisirt in farblosen Blättchen und platten Nadeln, welche sich in Wasser und Weingeist leicht lösen. Die wässerige Lösung des Salzes giebt mit Eisenchlorid eine intensiv kirschrothe Färbung. Silberlösung zur wässerigen Lösung des Salzes gebracht liefert anfänglich $\mathrm{AgCl}$, später bei einem Ueberschuf́s der Silberlösung tritt eine prächtig blaue Farbe der Lösung ein, wobei Metall abgeschieden wird. Fichtenholz färbt sich mit der wăsserigen Lósung des Salzes intensiz safrangelb. Das salzsaure Salz löst sich in mäfsig verdünnter Schwefelsäure farblos auf.

Mit Platinchlorid giebt die wässerige Lösung des Salzes einen blafsgelben, aus concentrisch gruppirten Nadeln bestehenden Niederschlag ron salzsaurem Monamidomethylen-brenzcatechinplatinchlorid. Dieser Niederschlag ist indefs leicht veränderlich.

Mit Goldchlorid entsteht eine purpurrothe Färbung, jedoch anfänglich kein Niederschlag; später scheidet sich Gold ab.

Wird das Salz mit Natronlauge übersättigt, so entrieht Aether der Mischung die freie Base, welche beim Verdunsten der mit Wasser gewaschenen Aetherlōsung als ein bräunlich gefärbtes Oel von stark basischer Reaction zurückbleibt, leicht löslich in Alkohol und Chloroform.

Durch Neutralisation dieser Substanz mit Oxalsäure oder Schwefelsäure wurden die entsprechenden Salze gewonner. Hiervon ist

das oxalsaure. Salz in Wasser ziemlich leicht löslich und krystallisirt in derben weifsen Nadeln.

Das Sulfat dagegen krystallisirt in äufserst zarten Nadeln, welche sich leicht in Wasser, etwas schwerer in Weingeist lösen. - 
Bei der Nitrirung von Piperonylsäure mittelst rauchender Salpetersäure wurde von Jobst und mir *) Dinitromethylenbrenzcatechin als Nebenproduct erhalten. Dasselbe läfst sich ebenfalls sehr leicht mittelst Zinnfeile und Salzsäure reduciren. Wird dann die vom Zinn durch Schwefelwasserstoff befreite klar filtrirte Lösung vor Luft geschützt abgedampft, so krystallisiren endlich weifse Blättchen eines salzsauren Salzes, des salzsauren Diamidomethylenbrenzcatechins. Die wässerige Lösung dieses Salzes färbt sich mit Platinchlorid dunkelbraunroth, mit Eisenchlorid intensiv grün. Es löst sich mit gelbbrauner Farbe in concentrirter Schwefelsäure, welche Lösung indefs auf Zusatz von wenig Wasser eine prächtig blaue Färbung annimmt. Ein Zusatz von concentrirter Schwefelsäure macht die blaue Farbe wieder verschwinden, Wasser erzeugt sie wieder.

Zur Darstellung der freien Base wurde das Salz mit Sodalösung zersetzt und die Base mit Aether ausgeschültelt. Beim Verdunsten des mit Wasser gewaschenen Aethers blieb ein krystallinischer, jedoch schmutzig grüner Rückstand der zum Theil veränderten Base. Durch Behandlung dieses Rückstandes mit Salzsäure wurde wieder das ursprüngliche Salz in Krystallen erhalten, die in einer gefärbten Mutterlauge eingelagert waren.

Ich gebe diese Notiz mit dem Bemerken, dafs das vorhandene Material nicht hinreichte, um die Formel dieser Base, welche voraussichtlich $\mathrm{C}_{7} \mathrm{H}_{8} \mathrm{~N}_{2} \mathrm{O}_{2}=\mathrm{C}_{8} \mathrm{H}_{2} \cdot \mathrm{CH}_{2} \cdot\left(\mathrm{NH}_{2}\right)_{2} \cdot \mathrm{O}_{2}$ sein wird, durch die Analyse festzustellen.

*) Diese Annalen $\mathbf{n a t} 75$. 